\title{
PTSD presenting as possession states in children and adolescents in rural Sri Lanka: A case series
}

\author{
J Herath, SR Perera
}

\section{Abstract}

Dissociative disorders are usually a result of trauma and stress. They may stem from chronic trauma such as repeated episodes of physical, emotional, or sexual abuse or may follow acute trauma. Dissociative symptoms such as possession states following trauma have been described in the literature, especially in children and adolescents. This article highlights three case reports where patients with PTSD presented with dissociative symptoms following significant traumatic events.

Key words: trance and possession, dissociation, posttraumatic stress disorder (PTSD)

SL J Psychiatry 2020; 11(2): 35-37

\section{Introduction}

Trance and possession states are categorized as dissociative disorders in the ICD 10, when there is a temporary loss of both the sense of personal identity, with full awareness of the surroundings (1). A dissociative subtype of post-traumatic stress disorder (PTSD) was added to DSM-5 recently, but little is known about this pattern of symptoms in young children and adolescents exposed to trauma $(2,3)$. We present three case reports where children or adolescents presented with dissociative symptoms in the form of possession states, against a background of significant trauma.

They were referred by the consultant pediatrician of the local hospital and all investigations including EEG were normal.

\section{Case Report 1}

Miss A, a 14-year old girl, presented with a 4-month history of being possessed by her dead grandfather. During these episodes she walked and gestured 'like a man' and spoke in a deep, hoarse voice. While being in the possessed state she had been aggressive towards her father and attempted to hit him on several occasions. The possession states had occurred at least twice a week over the previous 4 months.

She revealed that she disliked her father's habit of consuming alcohol because when he came home intoxicated, he would lock her in a room and physically assault her until she bled. She said this was her father's way of punishing her for not achieving good enough marks by his standards, at examinations. This had been a frequent occurrence over the last 2-3 years.

\section{Case Report 2}

Master B, a 15-year old schoolboy was brought by the family due to repeated possession states each time he visited the local kovil. He had appeared to become possessed by the goddess Paththini (a female deity) during the kovil rituals. During these episode he assumed a flexible posture and moved in a dance-like state with his eyes closed, assuming feminine postures and speaking in an effeminate manner with a high pitched voice. These states lasted for 2-3 minutes each time, after which he fell to the ground and woke up refreshed and alert. This behavior had been evident for the past 3-4 months.

He revealed that he was 'never quite himself' ever since inadvertently witnessing a gang of people assault and murder a villager by stabbing and slashing the body. This had happened about 8 months previously.

\section{Case Report 3}

Miss C, a 10-year old girl was brought due to repeated episodes of appearing to be possessed by a dead male, for 6-7 months. When possessed, she spoke in a deep voice, and showed mannerisms similar to a male. She revealed that her father, who was dependent on alcohol, would frequently abuse her and her older sister. The abuse had been going on for almost two years and was physical as well as sexual. She would hide in the 
woodland outside her home for many hours, sometimes spending the entire night out of doors. Her mother has been working in the Middle East for as long as she could remember.

All three patients presented with clear symptoms of dissociation, while also experiencing symptoms of PTSD, such as disturbances in sleep, irritability and inability to focus. They also had the unpleasant phenomena of reexperiencing the traumatic events, in the form of recurring nightmares and avoidance of events and places where the initial trauma occurred. They met the prerequisites for a diagnosis of PTSD, namely directly experiencing the traumatic event or witnessing the traumatic event in person, or experiencing first-hand repeated or extreme exposure to aversive details of the traumatic event. None of the patients had symptoms meeting criteria for a depressive episode.

All three patients were managed with bi-weekly sessions of trauma focused psychotherapy, and a SSRI antidepressant. Other important steps in the immediate management included necessary action being taken to ensure that they were safeguarded from further episodes of impending harm.

All three patients improved significantly; with no dissociative episodes at the end of three months in the second and third patients, and after five months for the first patient. At the time of writing, they had remained symptom free for more than six months.

\section{Discussion}

Dissociation is a common feature of PTSD and involves detachment from the overwhelming emotional content of the experience during and in the immediate aftermath of trauma $(4,5)$. Chronic psychological, sexual and physical trauma, as well as emotional neglect have been etiologically linked to dissociation, though acute traumatic events can also lead to dissociation $(5,6)$.

Evidence points towards two types of response to trauma; one being primarily dissociative and other predominantly intrusive and hyper-aroused. However, an individual with PTSD can show both response patterns, either simultaneously or at different time points $(7,8)$. These subtypes can be viewed as different extremes of emotional deregulation $(7,8)$. The first involves under-modulation, and the second overmodulation to the trauma, and each appears to have distinct CNS correlates (5). All three patients in this case series had a predo-minantly dissociative response.

Records of dissociation in children and adolescents with PTSD are scarce (7). A study from the US which included 297 children exposed to trauma showed that girls and children who were sexually abused were as twice and thrice more likely respectively to develop PTSD, with the dissociative subtype (3). The study reported that for every unit increase in parent avoidance symptoms or number of traumatic events, the odds of developing the dissociative subtype of PTSD increased significantly (3). The child described in case one was exposed to repeated traumatic events, which was likely to have increased the risk of her developing the dissociative subtype of PTSD.

\section{Conclusions}

While there are many reasons why children and adolescents may present with dissociative symptoms, psychiatrists should be aware that PTSD in children can present as trance and possession states, as part of the dissociative response to trauma. This case series highlights the importance of understanding the role of dissociation and the development of PTSD in children and adolescents, as it has significant implications when planning the overall management.

\section{Acknowledgements}

The authors wish to acknowledge all the patients and their families for providing detailed histories.

\section{Statement of contribution}

Both authors contributed to the writing of the case report.

\section{Conflicts of interest}

None declared.

J Herath, SR Perera, District General Hospital, Nuwara Eliya, Sri Lanka

Corresponding author: SR Perera

Email: sayuperera@yahoo.com

http://orcid.org/0000-0001-6824-8991

\section{References}

1. World Health Organization. The ICD-10 classification of mental and behavioural disorders: diagnostic criteria for research. World Health Organization; 1993.

2. American Psychiatric Association. Diagnostic and statistical manual of mental disorders (DSM-5®). American Psychiatric Pub; 2013. 
3. Hagan MJ, Gentry M, Ippen CG, Lieberman AF. PTSD with and without dissociation in young children exposed to interpersonal trauma. J of Affect Disord 2018; 227: 536-41.

4. Guina J, Baker M, Stinson K, Maust J, Coles J, Broderick P. Should posttraumatic stress be a disorder or a specifier? Towards improved nosology within the DSM categorical classification system. Curr psychiat reports 2017; 19(10): 66.

5. Lanius RA, Vermetten E, Loewenstein RJ, Brand B, Schmahl C, Bremner JD, Spiegel D. Emotion modulation in PTSD: Clinical and neurobiological evidence for a dissociative subtype. Am Journ of Psych 2010; 167(6): 640-7.

6. Vermetten E, Dorahy MJ, Spiegel D, editors. Traumatic dissociation: Neurobiology and treatment. Am Psych Pub; 2007.

7. Murray J, Ehlers A, Mayou RA. Dissociation and post-traumatic stress disorder: Two prospective studies of road traffic accident survivors. B J Psych 2002; 180(4): 363-8. 